\title{
An Investigation of Nurse Clinicians' Opinions on Standardized Training Methods for Nurses
}

\author{
Li Qiufeng ${ }^{1}$, Wang Yu ${ }^{2,}$, Liu Lina ${ }^{3}$, Zuo Feifei ${ }^{2}$, Hong Weixi ${ }^{2}$ \\ ${ }^{1}$ Department of Intravenous Catheter Nursing Clinic, The First Affiliated Hospital of Jinan University, Guangzhou, China \\ ${ }^{2}$ The First Affiliated Hospital, Jinan University, Guangzhou, China \\ ${ }^{3}$ Foshan Science and Technology College, Foshan, China
}

Email address:

linqu122@126.com (Wang Yu)

${ }^{*}$ Corresponding author

\section{To cite this article:}

Li Qiufeng, Wang Yu, Liu Lina, Zuo Feifei, Hong Weixi. An Investigation of Nurse Clinicians' Opinions on Standardized Training Methods for Nurses. Journal of Family Medicine and Health Care. Vol. 6, No. 1, 2020, pp. 15-19. doi: 10.11648/j.jfmhc.20200601.13

Received: February 5, 2020; Accepted: February 19, 2020; Published: February 28, 2020

\begin{abstract}
Objective: We try to explore new standardized training methods for nurses to further improve the standardized training system for nurse clinicians. Methods: Based on study of previous literature, we used self-designed questionnaires to investigate 262 nurse clinicians. Their opinions on through what training methods they most expect to receive the 25 standardized training contents and the common ways through which they acquire professional knowledge were collected. Results: Most nurses expect the 25 training contents for new nurses to be imparted through instruction of supervisors and intensive teaching mode; the nurses prefer diverisified training methods; they acquire professional nursing knowledge mainly through textbooks, lectures and training on special topics, internet, new media (WeChat, QQ or Official Accounts), literature database searching and other channels. There is significant difference in the number of nurses who acquire professional nursing knowledge through new media between new nurses, and middle and senior nurses $\left(\chi^{2}=5.828, \mathrm{P}=0.016\right)$. Conclusions: When giving standardized training for new nurses, we should choose appropriate training methods according to the training contents. Diversified training can meet different needs of different nurses. We encourage new standardized training mode combined with internet and new media to save training cost and improve training effect.
\end{abstract}

Keywords: Standardized Training, Training Method, Diversified Training, Nurse

\section{Introduction}

With the change of the medical model, people's higher demand for nursing care, and the continuous growth of hospital business at all levels, nurses are facing higher requirements for their nursing theoretical knowledge, nursing skill and quality. New graduated nurses are required to realize the transition from students to professional nurses, and should be proficient in the basic knowledge and skills of nursing so that they can be qualified for clinical nursing work. However, at present, wave of new nurses who are lack of standardized training in the clinical frontline in a short time, may pose a certain threat to the quality of clinical care and safety of the patients [1-3]. In 2016, the National Health and Family Planning Commission issued the Training Syllabus for New Nurses (Trial) [4] to further emphasize the necessity and importance of standardized training for new nurses to ensure the quality of clinical nursing work and the development of nursing talents which also reflects China's emphasis on training for new nurses. Newly graduated nurses are the most basic part of the nursing team. Their growth is related to the overall quality of the nursing team. Standardized training is an important means to help new nurses grow, and it is also an important part of training qualified nursing talents.

The current shortage of nursing talents and the increasing training costs makes how to effectively conduct standardized training for new nurses so that new nurses can meet clinical front-line needs as soon as possible an important issue? Some scholars have discussed the requirements of standardized training contents for nurses [5-7]. Their discussions cover topics such as strengthening the training of basic nursing knowledge, theory and skills, introducing training in emergency response abilities, first aid skills, etc. Their studies also focus on 
clinical practical work ability and multi-level and multi-form standardized training for nurses. However, studies on nurses' opinions on standardized training methods are still few. This study, combined with the literature on standardized training for new nurses, adopts a self-designed questionnaire survey to focus on new nurses' needs of standardized training methods, so as to provide a basis for further improving the standardized training system for new nurses.

\section{Methods and Participants}

\subsection{Design of Questionnaire}

Based on the relevant literature on standardized training for new nurses, the Training Syllabus for New Nurses (Trial) [4], and Standardized Training Materials for Nurses in Guangdong Province (Primary) [8], we designed a preliminary questionnaire for standardized training methods for new nurses. We selected ten clinical nurses for interviews and pre-surveys. After repeated revisions, we finished the final version of questionnaire which included the questionnaire for general situation and questionnaire for standardized training methods for new nurses. The questionnaire for standardized training methods for new nurses mainly consists of the most desirable training methods for nurses for the 25 standardized training contents and common channels for obtaining professional knowledge.

\subsection{Participants}

We used convenience sampling to include 300 nurses from 4 grade A class three general hospitals in Guangzhou as participants. The inclusion criteria were 1) nurses who graduated from nursing colleges, including technical secondary school, junior college, had undergraduate or higher education background; 2) those who passed Chinese Licensure Examination for Nurse; 3 ) those who have engaged in clinical nursing work at the chosen hospital for 3 months or more; 4) nurses who volunteered to participate in this investigation.

\subsection{Investigation Method}

After receiving consent from the selected hospitals, we conducted the investigation when the hospital organized intensive learning for the nurses. The questionnaires adopted same guidelines and anonymous surveys.

\subsection{Collection and Statistical Analysis of Data}

We numbered the valid questionnaires and used Epidata 3.1 software for double entry. SPSS13.0 statistical software was used to process the data. We conducted descriptive statistical analysis of the general situation and the choice of training methods of the participants using the mean, standard deviation and / or percentage. We employed chi-square test to explore the difference in the percentages of the nurses who made different choices between nurses at different levels $(\alpha=0.05)$.

\section{Results}

\subsection{Collection of Questionnaires and General Data of the Participants}

We distributed 300 questionnaires and collected 291 among which 29 questionnaires with blank items more than $20 \%$, errors and answers in a certain pattern were excluded. The 262 remained were valid questionnaires and the effective rate of the collected questionnaires was $90.0 \%$. The average age of 262 participants was $30.5 \pm 8.38$; their working years ranged from half a year to 23 years; 259 were females and 3 were males; 116 were new nurses (working years $\leq 3$ years) and 146 middle- and senior-level nurses (working years $>3$ years).

\subsection{Choices of the Standardized Training Methods for New Nurses}

The results of the training methods that the 262 nurses most wanted for the 25 standardized training contents for new nurses are shown in the Table 1. It can be seen from Table 1 that the training methods that nurses want are mostly instructor-led and intensive teaching methods. For specialized nursing operations, specialized instruments and equipment, most nurses $(>50 \%)$ chose instructor-led mode to learn and for first-aid knowledge and skills, precautions for taking medicines, emergency response plans, and hospital infection knowledge, they chose intensive teaching mode. In addition, nurses tend to choose diversified training methods for different training contents.

Table 1. Investigation of Standardized Training Methods for New Nurses $(n=262)$.

\begin{tabular}{|c|c|c|c|c|c|c|}
\hline \multirow{2}{*}{ Training contents } & \multicolumn{2}{|c|}{ Intensive teaching mode } & \multicolumn{2}{|c|}{ Instructor-guided mode } & \multicolumn{2}{|c|}{ Nursing round } \\
\hline & number & percentage $(\%)$ & number & percentage $(\%)$ & number & percentage $(\%)$ \\
\hline Basic nursing knowledge & 119 & 45.4 & 67 & 25.7 & 6 & 2.3 \\
\hline Specialized nursing knowledge & 101 & 38.5 & 105 & 40.1 & 29 & 11.1 \\
\hline Psychological nursing knowledge & 80 & 30.5 & 33 & 12.6 & 38 & 14.9 \\
\hline Critical thinking training & 50 & 19.1 & 67 & 25.4 & 69 & 26.1 \\
\hline Practice of nursing procedures & 74 & 28.2 & 51 & 19.4 & 80 & 30.4 \\
\hline Core nursing systems and norms & 123 & 46.9 & 68 & 21.6 & 14 & 5.3 \\
\hline Specialized nursing operation skills & 56 & 21.4 & 171 & 65.3 & 10 & 3.8 \\
\hline Use of specialized instruments and equipment & 68 & 26.0 & 166 & 63.3 & 3 & 1.1 \\
\hline First aid knowledge and skills & 139 & 53.0 & 87 & 33.2 & 7 & 2.7 \\
\hline Patient safety management & 91 & 34.7 & 68 & 25.9 & 64 & 24.5 \\
\hline Disease emergency response & 124 & 47.3 & 101 & 38.4 & 16 & 6.1 \\
\hline
\end{tabular}




\begin{tabular}{|c|c|c|c|c|c|c|}
\hline \multirow{2}{*}{ Training contents } & \multicolumn{2}{|c|}{ Intensive teaching mode } & \multicolumn{2}{|c|}{ Instructor-guided mode } & \multicolumn{2}{|c|}{ Nursing round } \\
\hline & number & percentage $(\%)$ & number & percentage (\%) & number & percentage (\%) \\
\hline Care for critically ill patients & 75 & 28.6 & 106 & 40.5 & 69 & 26.4 \\
\hline Terminal care & 83 & 31.6 & 87 & 33.3 & 13 & 5.0 \\
\hline Health education formulation and implementation & 74 & 28.2 & 60 & 22.8 & 71 & 27.2 \\
\hline Notes on the use of common drugs in specialty & 133 & 50.7 & 82 & 31.4 & 4 & 1.5 \\
\hline Notes for common specialist examination & 108 & 41.4 & 93 & 35.6 & 5 & 1.9 \\
\hline Communication principles and skills & 65 & 24.7 & 97 & 37.1 & 12 & 4.6 \\
\hline Emergency response plan & 149 & 56.9 & 98 & 37.4 & 0 & 0.0 \\
\hline Prevention and management of adverse events & 104 & 39.7 & 108 & 41.3 & 14 & 5.3 \\
\hline Hospital infection knowledge & 169 & 64.5 & 47 & 18.0 & 0 & 0.0 \\
\hline Emotion management & 75 & 28.6 & 21 & 8.0 & 0 & 0.0 \\
\hline Code of ethics and conduct in nursing & 97 & 37.0 & 54 & 20.7 & 0 & 0.0 \\
\hline Nursing etiquette and spirit & 82 & 31.3 & 45 & 17.3 & 0 & 0.0 \\
\hline Career planning & 118 & 44.9 & 52 & 19.9 & 0 & 0.0 \\
\hline Others (English, PPT making, etc.) & 74 & 28.2 & 14 & 5.3 & 0 & 0.0 \\
\hline
\end{tabular}

Table 1. Continued.

\begin{tabular}{|c|c|c|c|c|c|c|}
\hline \multirow{2}{*}{ Training contents } & \multicolumn{2}{|c|}{ Group learning } & \multicolumn{2}{|c|}{ New media } & \multicolumn{2}{|c|}{ Self-learning } \\
\hline & number & percentage $(\%)$ & number & percentage $(\%)$ & number & percentage $(\%)$ \\
\hline Basic nursing knowledge & 5 & 1.8 & 18 & 6.9 & 47 & 17.9 \\
\hline Specialized nursing knowledge & 8 & 3.1 & 7 & 2.7 & 12 & 4.5 \\
\hline Psychological nursing knowledge & 23 & 8.8 & 59 & 22.0 & 29 & 11.2 \\
\hline Critical thinking training & 39 & 14.9 & 21 & 8.0 & 17 & 6.5 \\
\hline Practice of nursing procedures & 36 & 13.7 & 13 & 5.2 & 8 & 3.1 \\
\hline Core nursing systems and norms & 11 & 4.2 & 26 & 9.9 & 20 & 7.6 \\
\hline Specialized nursing operation skills & 13 & 5.0 & 9 & 3.4 & 3 & 1.1 \\
\hline Use of specialized instruments and equipment & 13 & 5.0 & 12 & 4.6 & 0 & 0.0 \\
\hline First aid knowledge and skills & 16 & 6.5 & 12 & 4.6 & 0 & 0.0 \\
\hline Patient safety management & 18 & 6.9 & 14 & 5.3 & 7 & 2.7 \\
\hline Disease emergency response & 6 & 2.3 & 15 & 5.7 & 0 & 0.0 \\
\hline Care for critically ill patients & 9 & 3.4 & 3 & 1.1 & 0 & 0.0 \\
\hline Terminal care & 25 & 9.5 & 43 & 16.4 & 11 & 4.1 \\
\hline Health education formulation and implementation & 19 & 7.3 & 29 & 11.1 & 9 & 3.4 \\
\hline Notes on the use of common drugs in specialty & 22 & 8.4 & 12 & 4.6 & 9 & 3.4 \\
\hline Notes for common specialist examination & 28 & 10.7 & 18 & 6.9 & 9 & 3.5 \\
\hline Communication principles and skills & 34 & 13.0 & 33 & 12.6 & 21 & 8.0 \\
\hline Emergency response plan & 0 & 0.0 & 9 & 3.4 & 6 & 2.3 \\
\hline Prevention and management of adverse events & 26 & 9.9 & 6 & 2.3 & 4 & 1.5 \\
\hline Hospital infection knowledge & 16 & 6.1 & 21 & 8.0 & 9 & 2.4 \\
\hline Emotion management & 25 & 9.5 & 93 & 35.6 & 48 & 18.3 \\
\hline Code of ethics and conduct in nursing & 14 & 5.3 & 78 & 29.7 & 19 & 7.3 \\
\hline Nursing etiquette and spirit & 17 & 6.5 & 99 & 37.6 & 19 & 7.3 \\
\hline Career planning & 17 & 6.5 & 45 & 17.2 & 30 & 11.5 \\
\hline Others (English, PPT making, etc.) & 14 & 5.3 & 73 & 27.9 & 87 & 33.2 \\
\hline
\end{tabular}

\subsection{Common Channels for Acquiring Nursing Knowledge}

Nurses mainly obtain nursing professional knowledge through 5 channels: textbooks, special lectures and trainings, internet, new media (WeChat / QQ or official account) and literature databases. There is a difference between new nurses ( $\leqq 12$ months) and middle and senior nurses (working age $\geq 5$ years) in acquiring nursing professional knowledge through new media channels. The number of new nurses who acquire nursing knowledge through new media account for $48.3 \%$ while middle and senior nurses only account for $33.6 \%$, which is statistically different $\left(\chi^{2}=5.828, \mathrm{P}=0.016\right)$, as shown in Table 2 .

Table 2. Channels for Acquiring Professional Nursing Knowledge.

\begin{tabular}{lll}
\hline Channels for acquiring professional nursing knowledge & Number & Percentage (\%) \\
\hline Textbooks & 246 & 93.9 \\
Special lectures and training & 193 & 73.7 \\
Internet & 154 & 58.8 \\
New media (WeChat/QQ or official account, etc.) & 105 & $40.1^{*}$ \\
Literature databases & 28 & 10.7 \\
\hline
\end{tabular}

note:* new nurse ( $\leqq 12$ months) vs. middle and senior Nurses (working age $\geq 5$ years). 


\section{Discussion}

\subsection{Choosing Appropriate Training Methods for Different Standardized Training Contents}

The results of this study show that nurses tend to choose different training methods for different standardized training contents, which is consistent with other related research [9]. The reasons may be related to the characteristics of different training contents: first aid knowledge and skills, the use of commonly used drugs in specialty, emergency response plans, and hospital infection knowledge are relatively theoretical, generalized and abstract, and require systematic and consistent training. Intensive training and special lectures can help learners learn and memorize systematically. Specialist operations and the use of specialist equipment are relatively practical skills. Hence, nurses need to be trained under the guidance of a mentor in combination with cognitive and behavioral training. The practice of nursing procedures, care for critically ill patients, critical thinking training, formulation and implementation of health education, patient safety management and other theoretical contents are more integrated with clinical practice. That is to say training of these contents pays more attention to the training of clinical thinking and analytical skills, and nursing rounds and group discussion are more appropriate training methods. Analysis of the results of this survey suggests that the knowledge of first aid and hospital infection are applicable to the training for all new nurses, and intensive teaching method is recommended to effectively save training costs. Specialized skills are applicable training content for some specialized nurses and can be trained by instructors, which also can deepen the communication between nurses at different levels and ne nurses can obtain clinical work experience [10]. Therefore, when conducting standardized training for new nurses, appropriate training methods should be selected according to the training contents to improve the training effect.

\subsection{Employment of Diversified Training Methods to Meet the Needs of Standardized Training for New Nurses}

According to the results of this study, for the same content, different nurses prefer different training methods, which may be due to differences in nurses' individual learning preferences. It can be seen from table 1 that the training methods that nurses want are mostly instructor-led and intensive teaching methods. Hence, diversified training methods are recommended. According to Kolb's model of experiential learning [11], people show different learning tendencies during the learning process, including preferences for learning styles, which are generally divided into principle, experience, practical, and thinking style. People adopting principle style tend to learn through intensive teaching mode, lectures, etc. Those adopting experience and practical types prefer instructor-led mode, case studies and group discussions. Group learning is a training method that people belonging to thinking type prefer. Therefore, as an individual, each nurse has his/her own learning preferences. We suggested that in the standardized training, the new nurse's learning style and their personalized training method should be considered. Besides, diversified training methods should be adopted to meet the diversified needs of standardized training methods for nurses.

\subsection{Using Internet and New Media to Establish a Standardized Training Model for New Nurses}

In the survey, a considerable number of nurses choose new media as the means to learn various training contents. That is mostly because the network information explosion and popularity of smart phones render new media communication methods such as WeChat / QQ become inseparable from people's daily lives. Delivery of relevant training content through new media allows new nurses to make full use of time to simply and quickly learn relevant knowledge anytime and anywhere. In terms of the channels for obtaining nursing knowledge, although textbooks are still the most important ones, compared with middle and senior nurses, the proportion of new nurses using new media to obtain nursing knowledge is relatively higher. This may be related to the fact that new nurses are younger and more familiar with and keen on new media communication. This also provides an opportunity for the development of new media training models. In the United States, Taiwan and other regions, online media has become a popular training means for nurses [12-14]. However, it is relatively rare to provide training for new nurses through the Internet and new media in China [15]. With the advent of the mobile Internet era, especially the $5 \mathrm{G}$ era, the latest professional information can be searched via the Internet anytime and anywhere, and standardized training methods for nurses will become more diverse and personalized [16]. In the current highly networked era, how to make use of the characteristics of the Internet and new media to establish a standardized training model for new nurses, increase the interest of new nurses in learning professional knowledge, save training costs, and improve training effect, is still worth further discussion.

\section{Conclusions}

In summary, newly graduated nurses are the most basic part of the nursing team. Strengthening training in basic nursing knowledge, theory and skills, introducing training in emergency response abilities and first aid skills, and carrying out multi-level and multi-form standardized training for nurses are important means to help new nurses improve. During the standardized training for new nurses, appropriate training methods should be selected according to the standardized training contents. Diversified training methods can be adopted to meet the needs of different nurses for standardized training methods. It is also encouraged to, in combination of the characteristics of the Internet and new media, establish a standardized training model for new nurses to save training costs and improve training effect. 


\section{Acknowledgements}

This work was financially supported by the Special Innovation Project (Education and Research) by Department of Education of Guangdong Province (NO. 2015GXJK009).

\section{References}

[1] Mackinnon, K., Marcellus, L., Rivers, J., Gordon, C., \& Butcher, D. (2015). Student and educator experiences of maternalchild simulation-based learning: a systematic review of qualitative evidence protocol. JBI Database of Systematic Reviews and Implementation Reports, 13 (1), 14-26.

[2] Considine, J., \& Botti, M. (2004). Who, when and where identification of patients at risk of an in-hospital adverse event implications for nursing practice. International Journal of Nursing Practice, 10 (1), 21-31.

[3] V. Olišarová, L. Šedová, V. Tóthová, S. Bártlová, I. Chloubová, \& H. Michálková, et al. (2016). Areas of health-education of physicians and nurses in care for cardiac patients from the perspective of citizens of the czech republic. Neuro Endocrinology Letters, 37 (suppl 2), 5.

[4] LI Xiao-wei, WANG Zhi-wen, LI Shu-jia, \& SHANG Shao-mei. (2012). Current situation and reflection on training of new graduate nurses in china. Journal of Nursing Administration, 89 (s1), 1-2.

[5] Chang, S. J., Kwon, E. O., Kwon, Y. O., \& Kwon, H. K. (2010). The effects of simulation training for new graduate critical care nurses on knowledge, selfefficacy, and performance ability of emergency situations at intensive care unit. Korean Journal of Adult Nursing, 22 (4), 375-383.

[6] Altier, M. E., \& Krsek, C. A. (2006). Effects of a 1-year residency program on job satisfaction and retention of new graduate nurses. Journal for Nurses in Staff Development (JNSD), 22 (2), 70-77.

[7] Bratt, M. M., \& Felzer, H. M. (2012). Predictors of new graduate nurses' organizational commitment during a nurse residency program. Journal for Nurses in Professional Development, 28 (3), 108-19.
[8] ZHANG Zhen-lu, SHI Rui-fen, ZHENG Zhi-hui, LIU Yin-yan. (2015). Current situation and thinking on the training of specialized nurses in tertiary hospitals in guangdong province. Journal of Nursing Administration, 15 (12), 840-842.

[9] Eizenberg, M. M. (2011). Implementation of evidence-based nursing practice: nurses' personal and professional factors? Journal of Advanced Nursing, 67 (1), 33-42.

[10] Bsen, S. V., Bsen, M. S., \& Mohammad Ali Cheraghi. (2013). Implementation of evidence-based nursing practice for diabetic patients: an iranian experience. International Journal of Nursing Practice, 19 (S3), 73-80.

[11] Fleming, S., Mckee, G., \& Huntley-Moore, S. (2011). Undergraduate nursing students' learning styles: a longitudinal study. Nurse education today, 31 (5), 444-449.

[12] Wittmann-Price, R., Celia, L., \& Dunn, R. (2013). Successful implementation of evidence-based nursing practice: the indispensable role of staff development. Journal for Nurses in Professional Development, 29 (4), 202-4.

[13] Chang, W. Y., Sheen, S. T. H., Chang, P. C., \& Lee, P. H. (2008). Developing an e-learning education programme for staff nurses: processes and outcomes. Nurse Education Today, 28 (7), 822-828.

[14] Liu, W. I., Rong, J. R., \& Liu, C. Y. (2014). Using evidence-integrated e-learning to enhance case management continuing education for psychiatric nurses: a randomised controlled trial with follow-up. Nurse Education Today, 34 (11), 1361-1367.

[15] BlažUn, H., Kokol, P., \& Vošner, J. (2015). Research literature production on nursing competences from 1981 till 2012: a bibliometric snapshot. Nurse Education Today, 35 (5), 673-679.

[16] Liu, W. I., Liu, C. H., Liao C. Y., Chao P. R., \& Chu, K. C. (2020). Mobile community learning programme's effectiveness in case management for psychiatric nurses: A preliminary randomised controlled trial. Nurse Education Today, 85, 104259. 